\title{
Specific IgE Decision Point Cutoffs in Children with IgE-Mediated Wheat Allergy and a Review of the Literature
}

\author{
François Graham $^{\mathrm{a}, \mathrm{b}}$ Jean Christoph Caubet ${ }^{\mathrm{a}} \quad$ Salim Ramadan $^{\mathrm{a}} \quad$ David Spoerl $^{\mathrm{c}} \mathrm{d}$ \\ Philippe A. Eigenmann ${ }^{a}$ \\ a Pediatric Allergy Unit, University Hospitals of Geneva and University of Geneva, Geneva, Switzerland; ${ }^{b}$ Department \\ of Allergy and Immunology, Centre Hospitalier Universitaire Sainte-Justine and Centre Hospitalier de I'Université de \\ Montréal, Montreal, QC, Canada; ' ${ }^{\circ}$ ivision of Clinical Immunology and Allergy, Department of Medical Specialties, \\ University Hospital and School of Medicine, Geneva, Switzerland; ' Division of Laboratory Medicine, Department of \\ Pathology, Genetics and Laboratory Medicine, Geneva University Hospitals, Geneva, Switzerland
}

\section{Keywords}

Wheat allergy · Children · Food allergy · Component testing - Omega-5 gliadin · Wheat-specific lgE · Oral food challenge

\begin{abstract}
Background: Wheat lgE-mediated food allergy in children is one of the most frequent food allergies in westernized countries, affecting between 0.4 and $1 \%$ of children. Although 95\% predictive decision points have been determined for major allergens such as peanut, egg, and milk, the diagnostic performances of wheat-specific lgE (slgE) and wheat component testing are not well established. Objectives: The aim of this study was to determine slgE decision point cutoffs in children with IgE-mediated wheat allergy and provide a review of the literature. Method: A retrospective review of wheat oral food challenges was performed at the pediatric allergy unit of the University Hospitals of Geneva between 2004 and 2019. Performance characteristics for wheat and $\omega-5$ gliadin slgE were calculated and positive and negative OFC data were compared using the Mann-Whitney $U$ test. Results: A wheat slgE cutoff of $2.88 \mathrm{kU}_{\mathrm{A}} / \mathrm{L}$ had a sensitivity of
\end{abstract}

๑) 2020 S. Karger AG, Basel

karger@karger.com

www.karger.com/iaa
$95 \%$ (negative decision point), whereas a cutoff of $78.1 \mathrm{kU}_{\mathrm{A}} / \mathrm{L}$ had a specificity of $95 \%$ (positive decision point). When giving equal weight to sensitivity and specificity, the optimal cutoff point for wheat slgE was $12 \mathrm{kU}_{\mathrm{A}} / \mathrm{L}$, which gave a specificity of $70 \%$ and a sensitivity of $66.67 \%$. Conclusions: These findings suggest a high positive decision point for wheat $\operatorname{slgE}(78.1 \mathrm{kU} / \mathrm{L})$. This reinforces the importance of considering OFC in children with IgE-mediated wheat allergy to confirm diagnosis even in patients with relatively high wheat slgE values, as there is a risk of falsely mislabeling these patients as allergic.

(c) 2020 S. Karger AG, Basel

\section{Introduction}

Wheat IgE-mediated food allergy in children is one of the most frequent food allergies in westernized countries, affecting between 0.4 and $1 \%$ of children [1]. Wheat products are ubiquitous and difficult to avoid, which can

Edited by: H.-U. Simon, Bern.
Dr. François Graham

Pediatric Allergy Unit, University Hospitals of Geneva 6 rue Willy-Donze

CH-1211 Geneva 14 (Switzerland)

francois.graham@umontreal.ca 
Table 1. Patient challenge characteristics

\begin{tabular}{|c|c|c|c|c|}
\hline & Total & Positive OFC & Negative OFC & $p$ value $^{\mathrm{b}}$ \\
\hline Challenges & $50(100)$ & $30(60)$ & $20(40)$ & \\
\hline Male & $36(72)$ & $24(80)$ & $12(60)$ & 0.21 \\
\hline Age at OFC date, years & $4.04(0.76-12.3)$ & $4.65(0.76-11.3)$ & $2.98(1.14-12.3)$ & 0.20 \\
\hline \multicolumn{5}{|l|}{$\operatorname{sIgE}, \mathrm{kU}_{\mathrm{A}} / \mathrm{L}^{\mathrm{a}}$} \\
\hline Wheat $(n=50 / 50)$ & $13.2(0.27-100)$ & $89.95(1.2-100)$ & $6.345(0.27-78.4)$ & $<0.001$ \\
\hline$\omega-5$ gliadin $(n=23 / 50)$ & $0.56(0-42.3)$ & $0.935(0-42.3)$ & $0(0-4.08)$ & 0.057 \\
\hline
\end{tabular}

greatly impact the quality of life of children and their families. Although 95\% predictive decision points have been determined for major allergens such as peanut, egg, and milk $[2,3]$, the diagnostic performances of wheat-specific $\operatorname{IgE}(\mathrm{s} \operatorname{IgE})$ and wheat component testing are not well established.

\section{Materials and Methods}

We performed a retrospective review of wheat oral food challenges (OFCs) performed at the pediatric allergy unit of the University Hospitals of Geneva between 2004 and 2019. Children with a history of immediate IgE-mediated reactions and wheat sensitization with primary wheat avoidance were included. Patients with wheat-dependent exercise-induced anaphylaxis, and non-IgE-mediated wheat allergy were excluded. OFCs were performed and interpreted according to PRACTALL guidelines [4] and severity of reactions graded using the Sampson severity scale [5]. All wheat and $\omega-5$ gliadin sIgE were performed with the UniCAP ${ }^{\mathrm{TM}}$ system (Thermo Fisher, Uppsala, Sweden). Performance characteristics for wheat and $\omega-5$ gliadin sIgE were calculated, and positive and negative OFC data were compared using the Mann-Whitney $U$ test. Statistical analyses were performed using MedCalc (MedCalc Software, Ostend, Belgium) and GraphPad Prism version 8.0.1 (GraphPad Software Inc., San Diego, CA, USA). The project was approved by Geneva's Cantonal Research Ethics Committee.

\section{Results}

Forty-two children aged 1-12 years (median age 4 years) underwent 50 wheat OFCs. The patient challenge characteristics are described in Table 1. Thirty OFCs $(60 \%)$ were positive and $20(40 \%)$ were negative. Skin symptoms were most frequently encountered and developed in $24 / 30$ patients $(80 \%)$. Respiratory symptoms occurred in 15/30 (50\%), whereas head, eyes, ears, nose, and throat - HEENT - symptoms occurred in $9 / 30(30 \%)$ and gastrointestinal symptoms in $8 / 30$ (26.7\%). The median severity grade [5] was 3.5 (range 1-4). Overall, 21/30 $(70 \%)$ were treated with an anti-histamine, 5/30 (16.7\%) with corticosteroids, and 5/30 (16.7\%) with epinephrine. All symptoms occurred within the dose escalation period or 2-h surveillance period at the end of OFC, except for 1 patient who passed the OFC but had an immediate reaction the following day when introducing wheat (spaghetti) at home. This patient was considered as a positive OFC.

Median wheat sIgE levels in the positive OFC group were significantly higher than in the negative OFC group $\left(89.95 \mathrm{kU}_{\mathrm{A}} / \mathrm{L}\right.$, range $1.2-100$, and $6.345 \mathrm{kU}_{\mathrm{A}} / \mathrm{L}$, range $0.27-78.4$, respectively, $p<.001)$. The median $\omega-5$ gliadin level was $0.935 \mathrm{kU}_{\mathrm{A}} / \mathrm{L}$ (range $0-42.3$ ) in the positive $\mathrm{OFC}$ group (16/23), with a trend towards higher values than in the negative $\mathrm{OFC}$ group (median of $0 \mathrm{kU}_{\mathrm{A}} / \mathrm{L}$, range $0-4.08,7 / 23$ ), while not reaching statistical significance $(p=0.057)$. The median sIgE to wheat was significantly higher in patients aged 5 years and older $(n=20,49.15$ $\mathrm{kU}_{\mathrm{A}} / \mathrm{L}$, range 1.95-100) compared to patients 4 years and younger $\left(n=30,9.445 \mathrm{kU}_{\mathrm{A}} / \mathrm{L}\right.$, range $\left.0.27-100, p=0.048\right)$. No significant difference in median $\omega-5$ gliadin sIgE levels was seen between these two age groups $\left(0.295 \mathrm{kU}_{\mathrm{A}} / \mathrm{L}\right.$, range $0-24.7$, and $0.62 \mathrm{kU}_{\mathrm{A}} / \mathrm{L}$, range $0-42.3$, respectively, $p=0.93)$. There was a trend towards more severe reactions in patients with higher wheat sIgE, although this was not statistically significant (grade 3 and 4 reactions compared to grade 1 and 2 reactions; median $100 \mathrm{kU}_{\mathrm{A}} / \mathrm{L}$, range $7.37-100$, vs. $41.2 \mathrm{kU}_{\mathrm{A}} / \mathrm{L}$, range $1.2-100$, respectively, $p=0.095)$. On the other hand, $\omega-5$ gliadin $\operatorname{sIgE}$ levels did not correlate with reaction severity (grade 3 and 4 reactions compared to grade 1 and 2 reactions; median $0.62 \mathrm{kU}_{\mathrm{A}} / \mathrm{L}$, range $0-42.3$, vs. $2.14 \mathrm{kU}_{\mathrm{A}} / \mathrm{L}$, range $0-24.4$, respectively, $p=0.61$ ). 


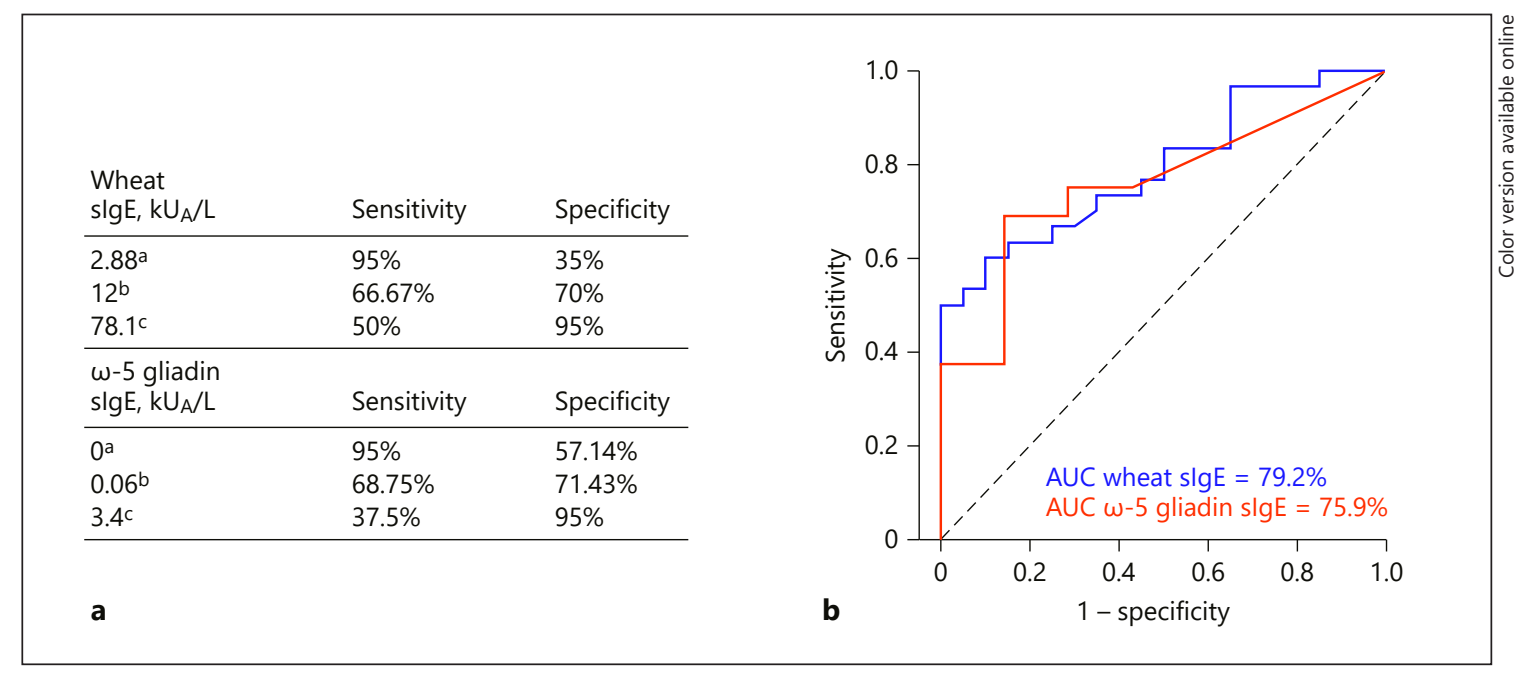

Fig. 1. a Sensitivity and specificity for various wheat $(n=50)$ and $\omega-5$ gliadin $(n=23)$ sIgE cutoffs. b ROC curve comparing the performance of wheat sIgE and $\omega-5$ gliadin. ${ }^{a}$ The negative decision point is defined as the cutoff producing a sensitivity of $95 \%$. ${ }^{b}$ The optimal cutoff point is the point where equal weight is given to sensitivity and specificity. ${ }^{c}$ The positive decision point is the cutoff producing a specificity of $95 \%$.

The performance characteristics of sIgE are reported in Figure 1a. A wheat sIgE cutoff of $2.88 \mathrm{kU}_{\mathrm{A}} / \mathrm{L}$ had a sensitivity of $95 \%$ (negative decision point), whereas a cutoff of $78.1 \mathrm{kU}_{\mathrm{A}} / \mathrm{L}$ had a specificity of $95 \%$ (positive decision points). When giving equal weight to sensitivity and specificity, the optimal wheat $\operatorname{sigE}$ cutoff point was $12 \mathrm{kU}_{\mathrm{A}} / \mathrm{L}$, which gave a specificity of $70 \%$ and a sensitivity of $66.67 \%$. A $\omega-5$ gliadin $\operatorname{sigE}$ cutoff of $0 \mathrm{kU}_{\mathrm{A}} / \mathrm{L}$ had a sensitivity of $95 \%$, whereas a $\omega-5$ gliadin $\operatorname{sigE}$ cutoff of $3.4 \mathrm{kU}_{\mathrm{A}} / \mathrm{L}$ had a specificity of $95 \%$. The optimal cutoff point for $\omega-5$ gliadin was $0.06 \mathrm{kU}_{\mathrm{A}} / \mathrm{L}$, which gave a sensitivity of $68.75 \%$ and a specificity of $71.43 \%$. AUCs for sIgE to wheat and $\omega-5$ gliadin were not statistically different (79.2 vs. $75.9 \%$, $p=0.78$; Fig. 1b). Wheat sIgE performance characteristics were not influenced by age (AUC $78.0 \%$ for children 5 years and above compared to an AUC of $77.3 \%$ for children 4 years and below, $p=0.96$ ).

\section{Discussion}

Our data on wheat sIgE are consistent with previous cutoffs described in the literature in children from Japan, Scandinavia, and the USA (Table 2). Overall, these data support a high positive decision point varying from 26 to $74.5 \mathrm{kU}_{\mathrm{A}} / \mathrm{L}[2,6,7]$, with a negative decision point around $1 \mathrm{kU}_{\mathrm{A}} / \mathrm{L}$, and an optimal cutoff point from 10.1 to 15.7 $\mathrm{kU}_{\mathrm{A}} / \mathrm{L}$. In our study, $18 / 20$ patients with sIgE under the positive cutoff point $\left(78.1 \mathrm{kU}_{\mathrm{A}} / \mathrm{L}\right)$ would have been inad- equately classified as wheat allergic on the basis of positive $\operatorname{sgE}\left(>0.35 \mathrm{kU}_{\mathrm{A}} / \mathrm{L}\right)$, if OFC had not been performed. This emphasizes the importance of performing OFCs to confirm wheat allergy, even in patients with positive wheat sIgE. The choice of the cutoff used can be adapted depending on the physician's clinical evaluation and the risk the physician is willing to accept taking into account the setting in which OFCs are performed. For example, the negative decision point $\left(2.88 \mathrm{kU}_{\mathrm{A}} / \mathrm{L}\right)$ could be used in a high-risk setting such as outpatient practice, whereas more at risk challenges using a cutoff under the positive decision point $\left(78.1 \mathrm{kU}_{\mathrm{A}} / \mathrm{L}\right)$ could be performed in a hospital setting, taking into account the physician's clinical evaluation.

$\omega-5$ gliadin sIgE was only performed in a subgroup of patients $(n=23)$. Although both wheat and $\omega-5$ gliadin yielded similar diagnostic performances (Fig. 1b), classification of a few patients differed when using these two tests with a cutoff of $0.35 \mathrm{kU}_{\mathrm{A}} / \mathrm{L}: 5$ patients with positive OFCs and positive wheat sIgE would have been falsely classified as negative on the basis of $\omega-5$ gliadin sIgE values (lower sensitivity). On the other hand, 6 patients with a negative wheat OFC would have been correctly classified as negative with $\omega-5$ gliadin sIgE as opposed to wheat sIgE, which were positive for those patients (higher specificity). Nonetheless, these 6 patients with negative $\omega-5$ gliadin had wheat $\operatorname{sIgE}$ ranging from 0.69 to $48.1 \mathrm{kU}_{\mathrm{A}} / \mathrm{L}$ and would have likely been challenged if using the $95 \%$ specificity cutoff. Although the sample size is small, these data are 
consistent with recent European studies, where component-resolved diagnosis added no additional information in the diagnostic workup of wheat-allergic children $[1,7$, 8]; on the other hand, a few earlier studies from Japan found increased diagnostic performance with $\omega-5$ gliadin sIgE when compared to wheat sIgE (Table 2) $[6,9,10]$.

Another point of discussion is whether the wheat sIgE/ total IgE ratio would improve diagnostic accuracy as potentially suggested with other foods [12]. On the other hand, in one recent study, the component-specific/total IgE ratio did not improve diagnostic performance of Ara h 2 and Cor a 14 in peanut/hazelnut-allergic children [13]. In our cohort, total sIgE was not systematically measured in patients as per food allergy guidelines [14]. We do not exclude, however, that this ratio could potentially improve wheat and $\omega-5$ gliadin sIgE diagnostic performance, and further data are needed.

The strength of our study is that all patients underwent standardized OFC based on PRACTALL guidelines, and a positive diagnosis was confirmed by OFC rather than suggestive clinical history as in some other cohorts (Table $2)$. In addition, a significant proportion of children challenged had high wheat sIgE levels $(n=25 / 50$ with wheat sIgE above $20 \mathrm{kU}_{\mathrm{A}} / \mathrm{L}$ ). On the other hand, limitations include missing $\omega-5$ gliadin data for some patients and a relatively small sample size.

All in all, these findings suggest a high positive decision point for wheat $\operatorname{sIgE}\left(78.1 \mathrm{kU}_{\mathrm{A}} / \mathrm{L}\right)$. This reinforces the importance of considering OFC in children with IgEmediated wheat allergy to confirm diagnosis even in patients with relatively high wheat sIgE values, as there is a risk of falsely mislabeling these patients as allergic. The decision to perform OFC and cutoff used should always take into account a risk/benefit assessment including clinical evaluation and OFC setting, since, as in any food challenge, severe reactions can occur. Prospective studies with a larger number of patients are needed to provide additional data on the utility of wheat sIgE and $\omega-5$ gliadin for the diagnosis of IgE-mediated wheat allergy.

\section{Statement of Ethics}

The study protocol was approved by the institute's committee on human research.

\section{Disclosure Statement}

Prof. Philippe Eigenmann received honoraria and research support from Thermo Fisher. All other authors have no conflicts of interest to declare.

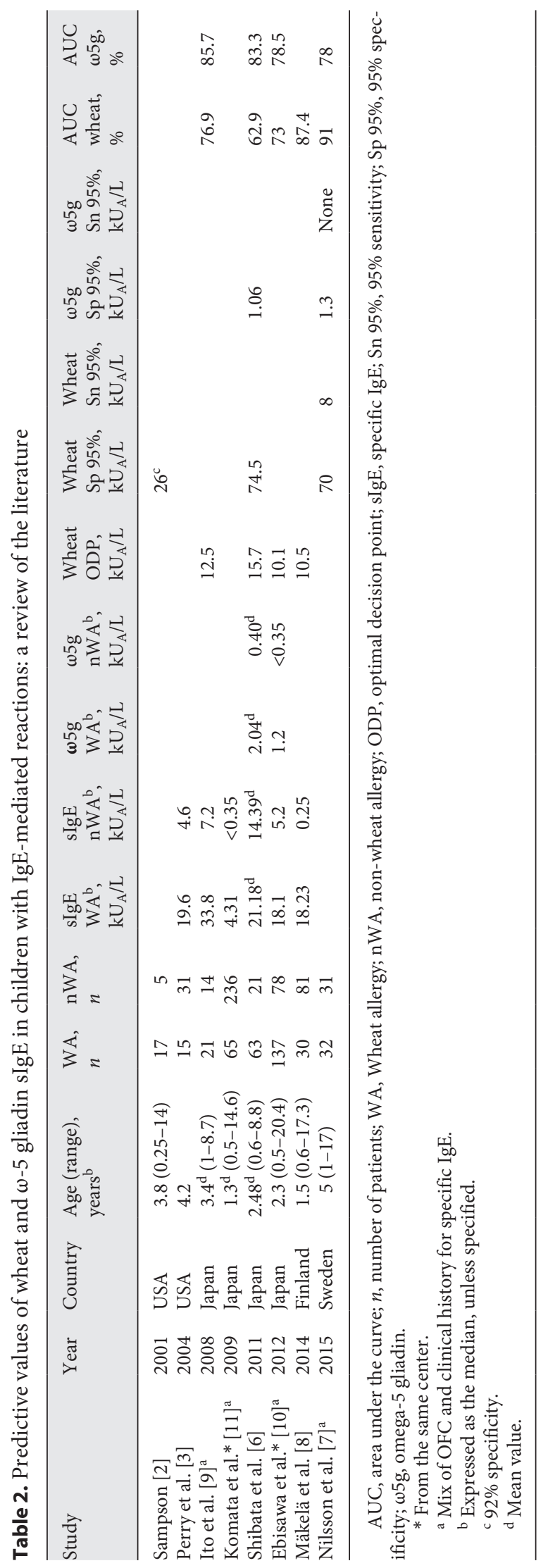




\section{Funding Sources}

This work was supported by the Ulrich Müller-Gierok foundation, Fonds de Recherche Santé Québec (FRQS), Fondation du Centre Hospitalier de l'Université de Montréal (CHUM), and Association des Allergologues et Immunologues du Québec (AAIQ).

\section{Author Contributions}

F.G. contributed to the design of the research, submitted the research to the institute's committee on human research, collected the data, contributed to the analysis of the results and to the writing of the manuscript. J.C.C., S.R., D.S., and P.A.E. contributed to the design of the research, to the analysis of the results, and to the writing of the manuscript.

\section{References}

1 Sievers S, Rawel HM, Ringel KP, Niggemann $\mathrm{B}$, Beyer K. Wheat protein recognition pattern in tolerant and allergic children. Pediatr Allergy Immunol. 2016 Mar;27(2):147-55.

2 Sampson HA. Utility of food-specific IgE concentrations in predicting symptomatic food allergy. J Allergy Clin Immunol. 2001 May;107(5):891-6.

3 Perry TT, Matsui EC, Kay Conover-Walker M, Wood RA. The relationship of allergenspecific IgE levels and oral food challenge outcome. J Allergy Clin Immunol. 2004 Jul; 114(1):144-9.

4 Sampson HA, Gerth van Wijk R, Bindslev-Jensen C, Sicherer S, Teuber SS, Burks AW, et al. Standardizing double-blind, placebo-controlled oral food challenges: American Academy of Allergy, Asthma \& Immunology-European Academy of Allergy and Clinical Immunology PRACTALL consensus report. J Allergy Clin Immunol. 2012 Dec;130(6):1260-74.

5 Sampson HA. Anaphylaxis and emergency treatment. Pediatrics. 2003 Jun;111(6 Pt 3): $1601-8$.
6 Shibata R, Nishima S, Tanaka A, Borres MP, Morita E. Usefulness of specific IgE antibodies to $\omega$-5 gliadin in the diagnosis and followup of Japanese children with wheat allergy. Ann Allergy Asthma Immunol. 2011 Oct; 107(4):337-43.

7 Nilsson N, Sjölander S, Baar A, Berthold M, Pahr S, Vrtala S, et al. Wheat allergy in children evaluated with challenge and $\operatorname{IgE}$ antibodies to wheat components. Pediatr Allergy Immunol. 2015 Mar;26(2):119-25.

8 Mäkelä MJ, Eriksson C, Kotaniemi-Syrjänen A, Palosuo K, Marsh J, Borres M, et al. Wheat allergy in children - new tools for diagnostics. Clin Exp Allergy. 2014 Nov; 44(11):1420-30.

9 Ito K, Futamura M, Borres MP, Takaoka Y, Dahlstrom J, Sakamoto T, et al. IgE antibodies to omega-5 gliadin associate with immediate symptoms on oral wheat challenge in Japanese children. Allergy. 2008 Nov;63(11): 1536-42.
10 Ebisawa M, Shibata R, Sato S, Borres MP, Ito K. Clinical utility of IgE antibodies to $\omega-5$ gliadin in the diagnosis of wheat allergy: a pediatric multicenter challenge study. Int Arch Allergy Immunol. 2012;158(1):71-6.

11 Komata T, Söderström L, Borres MP, Tachimoto H, Ebisawa M. Usefulness of wheat and soybean specific IgE antibody titers for the diagnosis of food allergy. Allergol Int. 2009 Dec; 58(4):599-603.

12 Federly TJ, Jones BL, Dai H, Dinakar C. Interpretation of food specific immunoglobulin $\mathrm{E}$ levels in the context of total IgE. Ann Allergy Asthma Immunol. 2013 Jul;111(1):20-4.

13 Grabenhenrich L, Lange L, Hartl M, Kalb B, Ziegert M, Finger A, et al. The componentspecific to total IgE ratios do not improve peanut and hazelnut allergy diagnoses. J Allergy Clin Immunol. 2016;137(6):1751-60.e8.

14 Sampson HA, Aceves S, Bock SA, James J, Jones S, Lang D, et al. Food allergy: a practice parameter update - 2014. J Allergy Clin Immunol. 2014;134(5):1016-25.e43. 